\title{
Performance Analysis of Double Inverter Fed Wound Rotor Induction Motor using Fuzzy and PI Controller
}

\author{
I. Thangaraju \\ Barrage Power House-I / Hydro Generation, \\ Tamil Nadu Electricity Board, \\ Mettur Dam, Tamilnadu, India 636452
}

\author{
M. Madheswaran \\ Centre for Advanced Research, \\ Muthayammal Engineering College, \\ Rasipuram, Tamilnadu, India 637408
}

\begin{abstract}
This paper proposes some design approaches combining PI control technique and fuzzy logic. This system has been designed to have two controllers, one Fuzzy based controller for stator and another one PID based for rotor. Such a mixed implementation leads to a more effective control design objectives such as steady state and transient characteristics of the closed loop system. Fuzzy logic is integrated to overcome the problems with uncertainties in the motor parameters. Induction motors are characterized by complex, highly non-linear and time varying dynamics. The advent of vector control techniques has partially solved induction motor control problems. Also they are sensitive to drive parameter variations such as the rotor time constant and an incorrect flux measurement or estimation at low speeds. If the conventional controllers are used the performance may deteriorate. Fuzzy logic based controller deal such variations more effectively. A simulation study of Fuzzy/PID based Stator/Rotor vector control is presented. The effectiveness of these controllers is demonstrated for different operating conditions of the drive system.
\end{abstract}

\section{Keywords}

Wound Rotor Induction Motor, Fuzzy Logic Controller, Field Oriented Control.

\section{INTRODUCTION}

Prior to the 1950's most factories used DC motors because three phase induction motors could only be operated at one frequency [1]. Now thanks to advances in power electronic devices and the advent of modern technology fast, reliable and cost effective control of induction motors is now common place. Over the past two decades a great deal of work has been done into techniques such as Field Oriented Control (vector control), Direct Torque Control. Another emerging area of research involves the application of fuzzy logic control.

Induction motor drives with full power control on the stator side are commonly used in industrial applications. Although either a cagetype or wound rotor induction machine can be used in the drive, the former is always preferred in terms of low weight, low cost, low rotor inertia, speed limitation, maintenance and reliability. One feature of the latter is that the slip power becomes easily available from the slip rings, which can be either mechanically or electronically controlled for motor speed adjustment [2-3]. The wound rotor induction motor takes this advantage. The application of WRIM motor in industrial environment has increased due to the high performance and high starting torque as suitable drive system. Slip-power recovery scheme is an efficient method of speed control of wound rotor induction motor. Slip power for adjusting motor speed can be recovered through static converters instead of useless dissipation on resistors. Slip power recovery drives have been used in some applications such as large capacity pumps and fan drives, variable-speed wind energy systems, shipboard variable - speed / constant - frequency systems, variable-speed hydro pumps/generators and utility system flywheel energy storage systems. The slip energy recovery drives (SERD) known as Scherbius system [4], is low cost, simple control circuitry and high efficiency even at a low-speed range. A SERD transfers power that is normally wasted in the rotor of an induction machine back to the ac mains supply to improve overall drive efficiency. The main draw-back of this scheme is the poor supply power factor due to reactive power drawn from the source both by motor as well as line commutated inverter. The drive power factor is found to be optimized for applications requiring a narrow range of speed control and a large load torque, where significant real power is returned via the inverter. A problem of SERD is, having lower power factor. Many improvements and new schemes are presented in [2-4] to improve the line power factor,Improved performance such as current harmonic reduction, power factor, and reactive power of SERD.

G D Marques and P Verdelho [5] presented a different circuit configuration in which a boost up chopper connects the rotor rectifier to a dc link of voltage controlled line commutated inverter connected in parallel with a capacitor. Yoshika Kawabata, et al [6], proposed a vector controlled inverter fed wound rotor induction motor for high power applications. Study of these papers revealed that these schemes have some limitations as (i) speed control range is small to reduce the cost of the drive; (ii) a number of starting equipments are required, eg, starting liquid resistors, isolators, circuit breakers, fuses, transfer-over switch, speed sensing devices; (iii) shoot through fault often damage the drive; (iv) supply line voltages increase whenever a large amount of power is recovered to the mains; and (v) Large harmonics are injected in the supply line due to switching of at least six switches of the recovery inverter. However, the control methods and circuitry seem to be complicated.

A modified slip energy recovery drives by using the dc link slip power recovery with double converter one on stator side and other on rotor side is proposed in order to improve supply power factor in the wide range of speed variations.

For high dynamic performance industrial applications, their control remains a challenging problem because they exhibit significant non-linearities and many of the parameters, mainly the rotor resistance, vary with the operating conditions. Field orientation control (FOC) or Vector control of an Induction motor achieves decoupled torque and flux dynamics leading to 
independent control of the torque and flux as for a separately excited DC motor. FOC methods are attractive but suffer from one major disadvantage: they are sensitive to motor parameter variations such as the rotor time constant and an incorrect flux measurement or estimation at low speeds. Consequently, performance deteriorates and a conventional controller such as a PID is unable to maintain satisfactory performance under these conditions [7-9].

In this paper a composite control is introduced with Indirect Field-Oriented Controller for Controlling Induction Motor. Here the stator side converter is controlled by Fuzzy logic based FOC and the rotor side converter is controlled by an ordinary PID based FOC. The fuzzy logic controller (FLC) is follows the interpretation of linguistic IF-THEN rules. The parameters of the Fuzzy Logic Controller does not affected by the machine parameters because the fuzzy logic do not need any machine parameters. So the Robustness of the system is improved.

These controllers are evaluated under MATLAB simulations for a variety of operating conditions of the drive system and the results demonstrate the ability of the control structures to improve the performance of the drive system.

\section{MATHEMATICAL MODELLING OF THE PROPOSED SYSTEM}

Figure 1 shows the block diagram of the proposed system. The system consists of uncontrolled rectifier with filter capacitor and the doubly fed Wound Rotor Induction Motor (WRIM). Salient advantages of the proposed system include the following. Machine current is almost sinusoidal hence it reduces the harmonic copper loss. Line side power factor is unity with no harmonic current injection. Inverters can generate programmable excitation for the machine. Continuous slip power recovery for all speed of the machine is possible. Power can flow in either direction of the inverters and permitting the machine to run on both directions. Similarly, regenerative braking can quickly stop the machine. If this system is used in wind generation, autonomous operation of the system is possible with either a start-up capacitor or with a battery on the dc link. Extremely fast transient response is possible. Multiple systems can be operated in parallel. Super synchronous speed of operation is possible.

The stator side converter is controlled by fuzzy based field oriented controller which utilizes the actual speed and the stator currents. Similarly the rotor side converter is controlled by a PID based field oriented controller which utilizes the actual speed and the rotor currents.

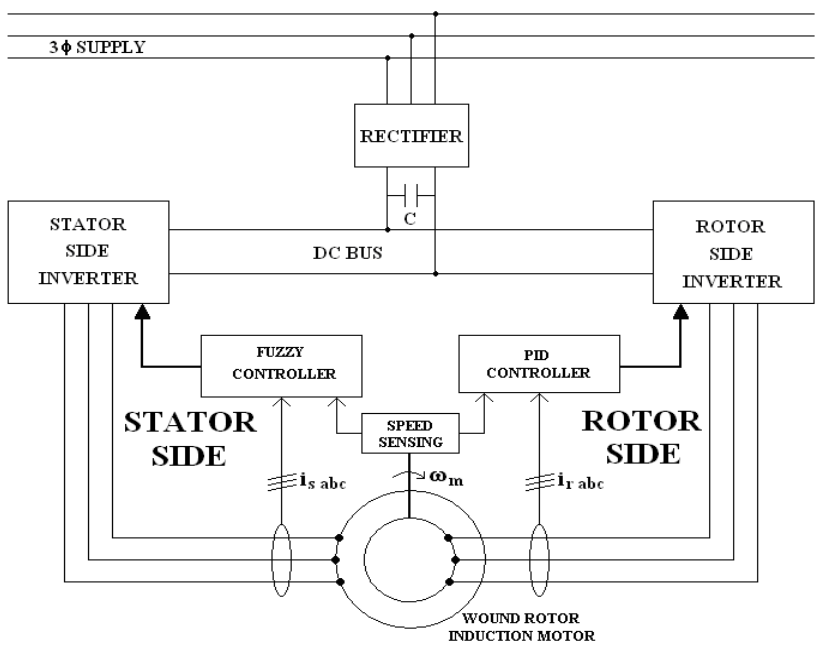

Fig 1. Block diagram of the proposed system

Hence, the slip-power is fed back to the motor itself. The operating principle of the proposed scheme is different from other schemes, in the sense that the slip-power recovered is being fed back to the motor without coupling any other machine with the Wound Rotor Induction Motor.

The $d-q$ dynamic model of the motor with the reference frame fixed to the stator is given in equation 1 .

$$
\begin{gathered}
\frac{d}{d t}\left[\begin{array}{c}
i_{d s}^{s} \\
i_{q s}^{q} \\
i_{d r}^{s} \\
i_{q r}^{q}
\end{array}\right]=\frac{1}{L_{\sigma}^{2}}\left[\begin{array}{cccc}
L_{r} & 0 & -L_{m} & 0 \\
0 & L_{r} & 0 & -L_{m} \\
-L_{m} & 0 & L_{s} & 0 \\
0 & -L_{m} & 0 & L_{s}
\end{array}\right]\left[\begin{array}{c}
V_{d s}^{s} \\
V_{q s}^{s} \\
V_{d r}^{s} \\
V_{q r}^{s}
\end{array}\right]+ \\
\frac{1}{L_{\sigma}^{2}}\left[\begin{array}{cccc}
-R_{s} L_{r} & \omega L_{m}^{2} & R_{r} L_{m} & \omega L_{r} L_{m} \\
-\omega L_{m}^{2} & -R_{s} L_{r} & -\omega L_{r} L_{m} & R_{r} L_{m} \\
R_{s} L_{m} & -\omega L_{s} L_{m} & -R_{r} L_{s} & -\omega L_{s} L_{m} \\
\omega L_{s} L_{m} & R_{s} L_{m} & \omega L_{s} L_{m} & -R_{r} L_{s}
\end{array}\right]\left[\begin{array}{c}
i_{d s}^{s} \\
i_{q s}^{q} \\
i_{d r}^{s} \\
i_{q r}^{q}
\end{array}\right]
\end{gathered}
$$

Where

$$
L_{\sigma}=\sqrt{L_{s} L_{r}-L_{m}^{2}}
$$

The electromagnetic torque is found from equation 2 .

$$
T_{e}=\frac{2 p L_{m}}{3 L_{r}}\left(i_{q s}^{s} \phi_{d r}^{s}-i_{d s}^{s} \phi_{q r}^{s}\right)
$$

where

$$
\phi_{d s}^{s}=L_{r} i_{d r}^{s}+L_{m} i_{d s}^{s}
$$

and 


$$
\phi_{q r}^{s}=L_{r} i_{q r}^{s}+L_{m} i_{q s}^{s}
$$

are the rotor flux components expressed in the stator reference frame. The field orientation principle is based on the following conditions, which are expressed in the excitation reference frame:

$$
\phi_{q r}^{e}=0, \quad \phi_{d r}^{e}=\text { cons } \tan t
$$

Hence the equations ensuring the field orientation are expressed in equation 3 and 4 .

$$
\begin{aligned}
i_{d s}^{e^{*}} & =\frac{1+T_{r} s}{L_{m}} \phi_{d r}^{e^{*}} \\
i_{d s}^{e^{*}} & =\frac{T_{e^{*}}}{K_{T}^{\phi_{d r}^{*}}}
\end{aligned}
$$

Where $\operatorname{Tr}=\mathrm{L}_{\mathrm{r}} / \mathrm{R}_{\mathrm{r}}$ is the rotor time constant.

Under these conditions, the induction machine is transferred into a linear current/torque converter as shown in equation 5 .

$$
T_{e}=K_{T} \phi_{d r}^{e} i_{q s}^{e}
$$

Hence the rotor torque and flux may be controlled separately through $i_{\mathrm{qs}}$ and $i_{\mathrm{ds}}$ respectively.

The $\mathrm{qd}_{\mathrm{e}}-\mathrm{qd}_{\mathrm{s}}$ transformation is shown in equation 6 and 7 .

$$
\begin{aligned}
& i_{q s}^{*}=i_{q s}^{r^{*}} \cos \theta_{r f}^{*}+i_{d s}^{r^{*}} \sin \theta_{r f}^{*} \\
& i_{d s}^{*}=-i_{q s}^{r^{*}} \sin \theta_{r f}^{*}+i_{d s}^{r^{*}} \cos \theta_{r f}^{*}
\end{aligned}
$$

The equation from 8 to 10 shows the $\mathrm{qd}_{\mathrm{s}}$-abc transformation.

$$
\begin{aligned}
& i_{a}^{*}=i_{q s}^{*} \\
& i_{b}^{*}=-\frac{1}{2} i_{q s}^{*}-\frac{\sqrt{3}}{2} i_{d s}^{*} \\
& i_{c}^{*}=-\frac{1}{2} i_{q s}^{*}+\frac{\sqrt{3}}{2} i_{d s}^{*}
\end{aligned}
$$

Here $\theta_{\text {ref }}$ represents the sum of slip and rotor angles.

A sinusoidal current source of variable magnitude and frequency is used to represent the fundamental component of the actual PWM inverter waveform. This avoids lengthy simulation times caused by the PWM switching.

\section{MOTOR SPEED CONTROL FROM ROTOR/STATOR SIDES}

The machine model of the system is shown in figure 2 . The rotor-side currents do not have any fluctuations when rotor flux magnitude is kept constant. If the stator-side currents are controlled, the rotor-side currents are generated automatically.
Thus, the rotor-side inverter voltage reference is generated just to keep $\Psi_{\mathrm{r}}$ constant at its rated value at all rotor supply frequencies.

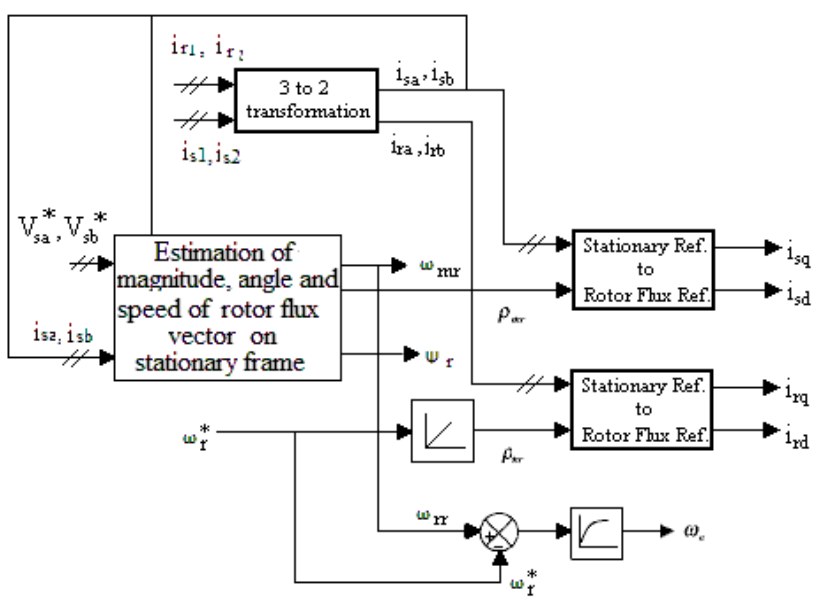

Fig.2. Machine model

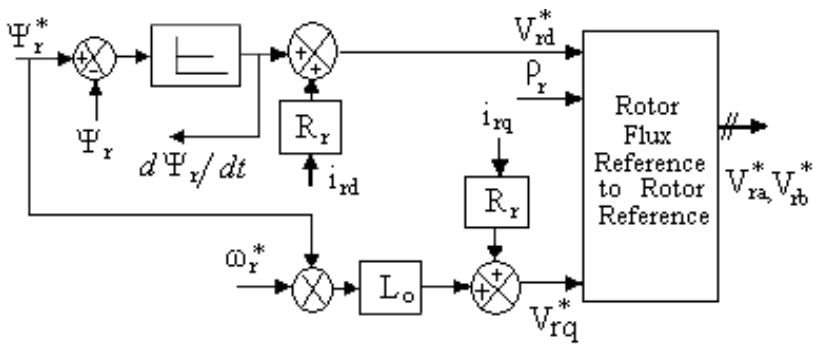

Fig.3. Block diagram of Rotor side controller

A simple PID controller serves this purpose easily. At any particular rotor speed, the PID controller directly controls the rotor flux angular velocity with respect to the rotor. The stator supply frequency, which is equal to the rotor flux speed with respect to the stator, has a unique value.

Here the fuzzy logic controller is used to control the stator side controller of the motor. The block diagram of the Fuzzy Logic Controller is shown in Fig. 4 and the Fuzzy logic Rules used in the controller is shown in table1.

The FLC rules are based on

\section{Ri: IF Ai AND Bi THEN Ci}

The controller structure is illustrated in fig.5.

Overall controller block diagram of the drive with various subblocks is given in fig.6. These blocks are explained later. It appears that fuzzy logic based control is most appropriate for performance improvement of the doubly fed systems [4]. The controller block diagram of the drive uses the power circuit which is shown in Fig.1.The line power factor is unity. Vector control permits fast transient response of the system. 


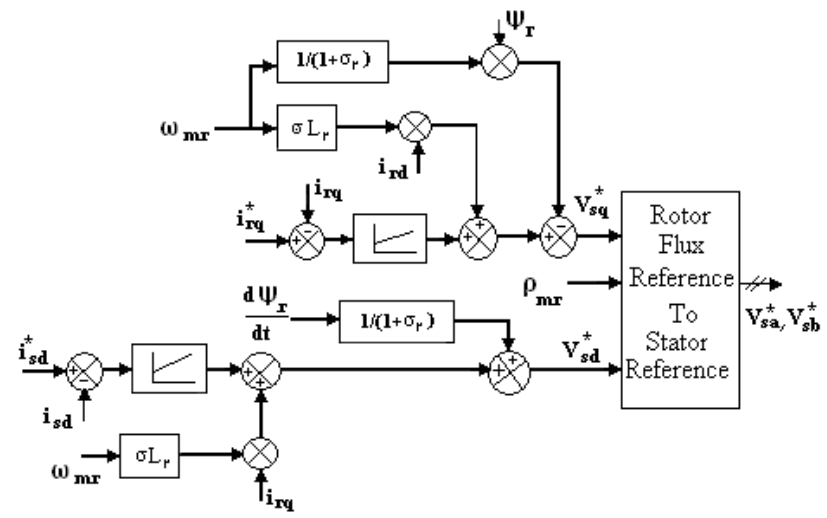

Fig.4. Block diagram of Stator side controller

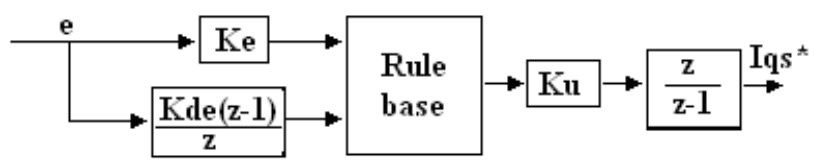

Fig.5. Structure of the Fuzzy Logic Controller

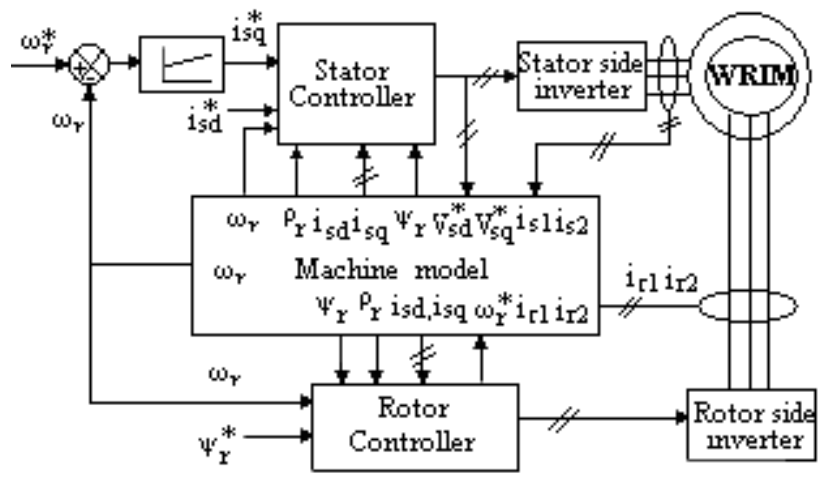

Fig.6. Overall controller block diagram of the proposed system

The speed loop will generate the torque component of machine current so as to balance the developed torque with the load torque. The variable voltage variable frequency power from the rotor at varying speed will be rectified and pumped to the dc link. The dc link voltage controller will regulate the line power (i.e., the line active current) so that the link voltage always remains constant. The system can be satisfactorily controlled for start-up and regenerative braking shutdown modes besides the usual mode of operation.

The inverter switch can be a Power Transistor, SCR, GTO, and IGBT, Power MOSFET or similar switching device. In order to get high switching frequency (up to $100 \mathrm{KHz}$ ) the Power MOSFET may be taken as a switching device. Normally on state drop in the switch is small and it is neglected [8]. When the gate pulse is applied the device is turned on. During the period the input supply connects with the respective motor terminals. When the gate pulse is removed the device is turned off and the motor terminals disconnected from the input supply.

\section{SIMULATION OF THE PROPOSED SYSTEM}

The simulation of the proposed system is done based on simulink-block set and equation modeling technique, using MATLAB/simulink toolbox. The complete simulink model developed is given in Figure 7.

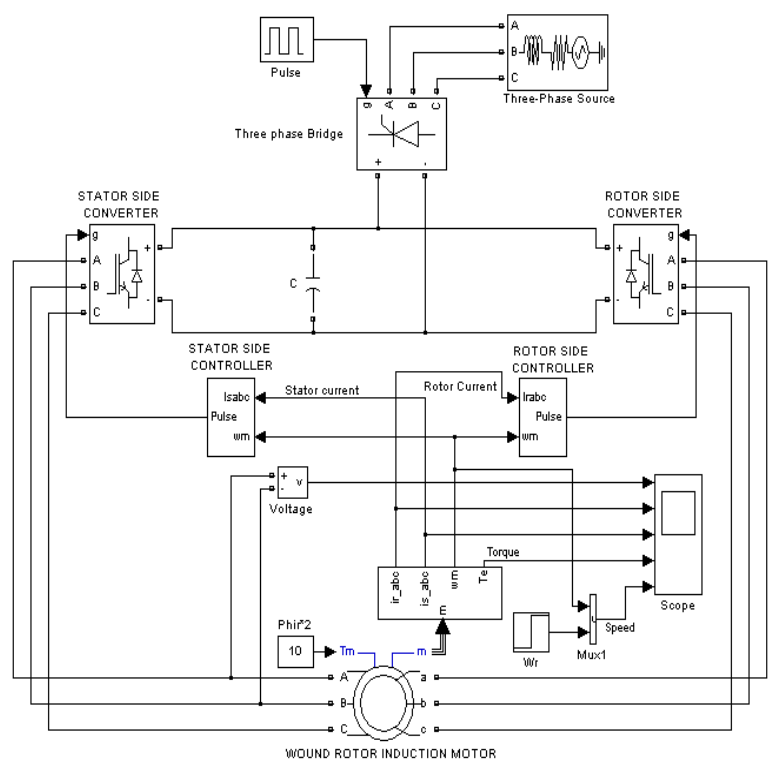

Fig 7. Simulink Model of the proposed system

The fuzzy controller block from fuzzy logic toolbox is used to test and evaluate the proposed fuzzy controller.

The structure of the stator side Fuzzy controller is represented in figure 8 in the form of flow chart. The similar structure is adopted for Rotor side PID controller also.

\subsection{Implementation of Stator side Fuzzy and Rotor side PID Controller in MATLAB / Simulink}

The effective and efficient control using fuzzy logic has emerged as a tool to deal with uncertain, imprecise or qualitative decision making problems [7 to 9]. The FLC involves four stages namely Fuzzification, Rule-Base, Inference engine and Defuzzification. In this work the Mamdani type controller is used. This controller has the membership function in the out put variable which will gives accurate result.

In Fuzzy logic system the linguistic variables are used instead of numerical variables. The process of converting a numerical variable (real number or crisp variables) in to a linguistic variable (fuzzy number or fuzzy variable) is called fuzzification.

In this work, the motor variables are speed $\left(\omega_{\mathrm{m}}\right)$ and stator current $\left(i_{\text {sabc }}\right)$. The stator side converter is controlled by FLC. The reference speed and the actual speed are given as input to the FLC. The error is found by comparing the actual speed $\omega_{\mathrm{m}}$ with reference speed $\omega_{\mathrm{r}}$. From the error e the stator quadrature 
current $\mathrm{i}_{\mathrm{qs}}$ and the stator change in quadrature current $\mathrm{di}_{\mathrm{qs}}$ is calculated. Then the $\mathrm{i}_{\mathrm{qs}}$ error and $\mathrm{di}_{\mathrm{qs}}$ are fuzzified.

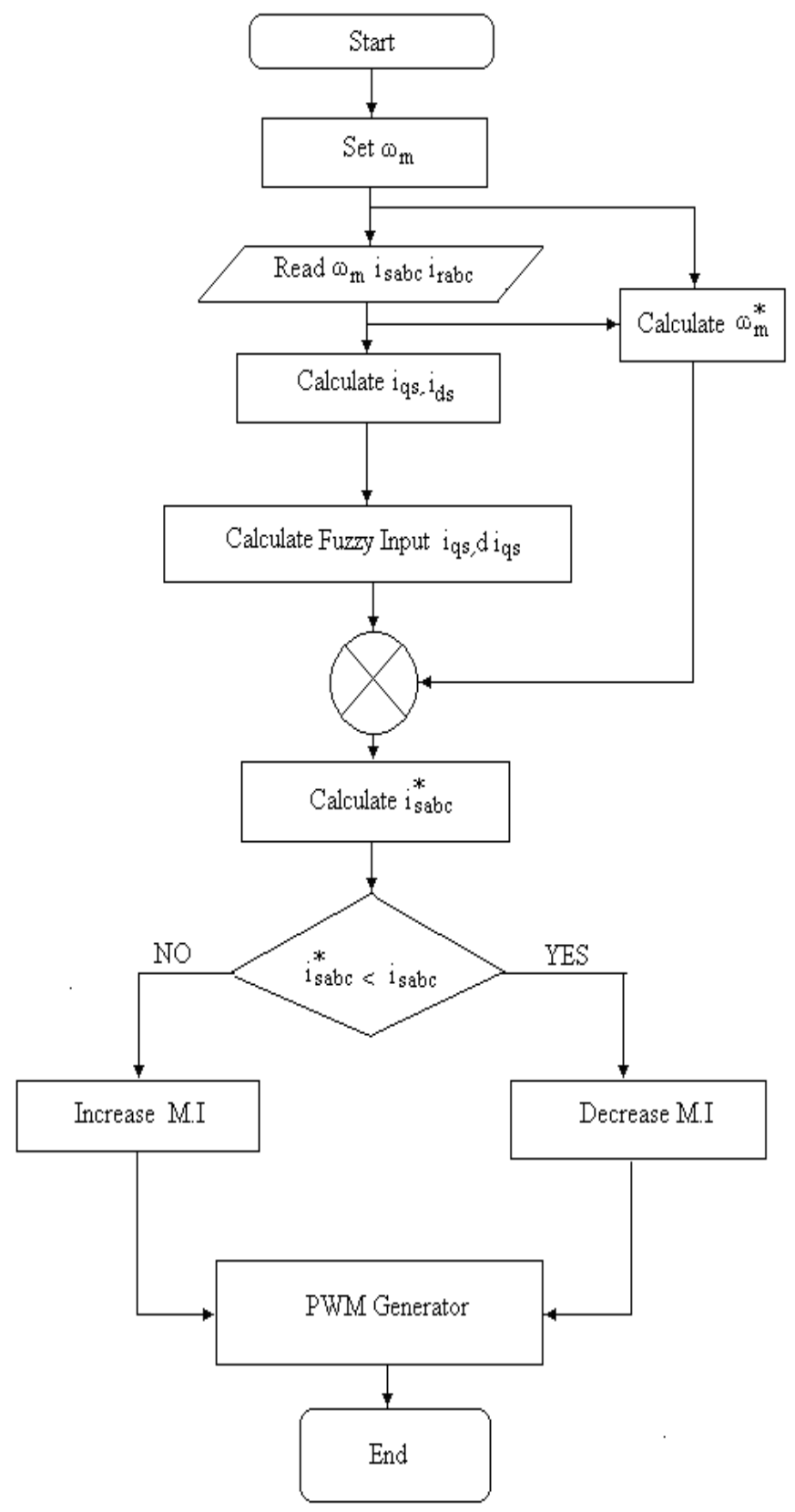

Fig 8. Structure of the fuzzy controller for stator side

Seven linguistic variables are used for the input variable $\mathrm{i}_{\mathrm{qs}}$ and $\mathrm{di}_{\mathrm{qs}}$. That are negative big (NB), negative medium (NM), negative small (NS), zero (Z), positive small (PS), positive medium (PM) and positive big (PB). There are many types of membership functions, such as triangular-shaped, Gaussian, sigmoidal, pi-shaped trapezoidal-shaped, bell-shaped etc. the triangular membership function is used for simplicity and also to reduce the calculations [5] and [7].

The reverse process of fuzzification is called defuzzification. The linguistic variables are converted in to a numerical variable [5]. As the centroid method is considered to be the best wellknown defuzzification method, it is utilized in the present model.

The defuzzified output is the reference quadrature current $i_{q}{ }^{*}$. The reference stator current $\mathrm{i}_{\text {sabc }} *$ is calculated from the $\mathrm{i}_{\mathrm{q}}{ }^{*}, \mathrm{i}_{\mathrm{d}} *$ and theta. This reference stator current is utilized for generating the PWM signals for the stator side inverter.The input and output fuzzy membership functions are shown in Figure 9.
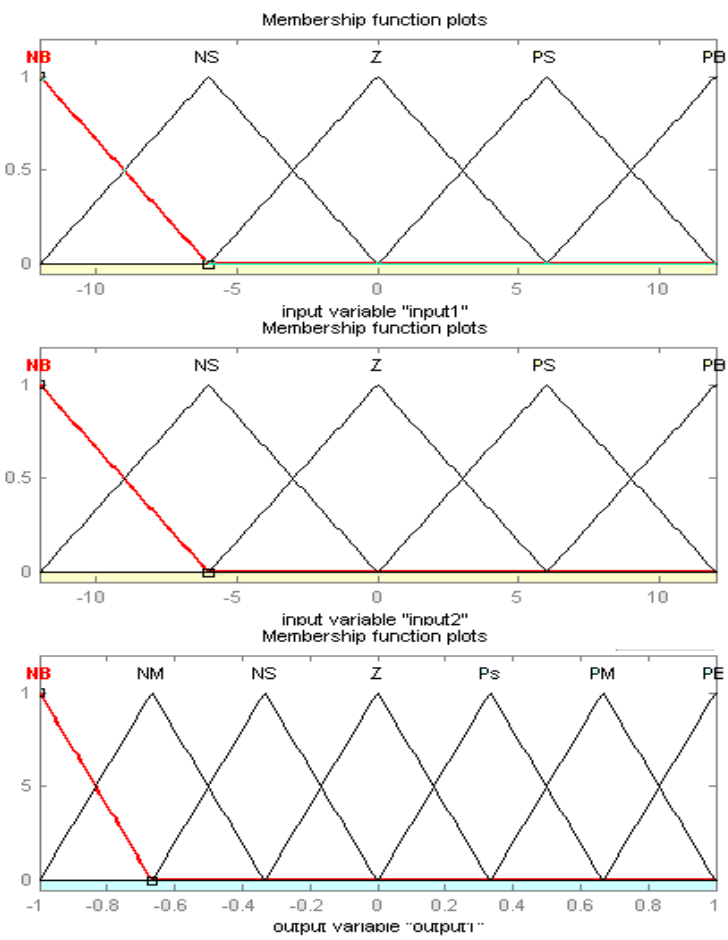

Fig 9. Fuzzy memberships used for simulation

The control rules that relate the fuzzy output to the fuzzy inputs are derived from general knowledge of the system behavior, also the perception and experience. However, some of the control rules are developed using "trial and error" method [16].

The general rule can be written as

\section{If $i_{s q}$ is $X$ and $d i_{s q}$ is $Y$, then $i_{q}$ * is $Z$}

where $\mathrm{X}, \mathrm{Y}$ and $\mathrm{Z}$ are the fuzzy variable for $\mathrm{i}_{\mathrm{sq}}, \mathrm{di}_{\mathrm{sq}}$ and $\mathrm{i}_{\mathrm{q}}{ }^{*}$ respectively [6].

The rule table for the designed fuzzy controller is given in the Table 1. The element in the first row and first column means that 


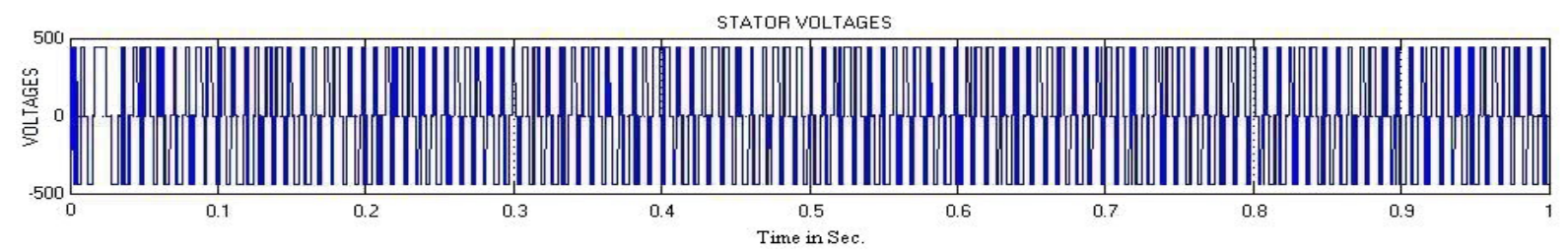

STATOR CURRENTS
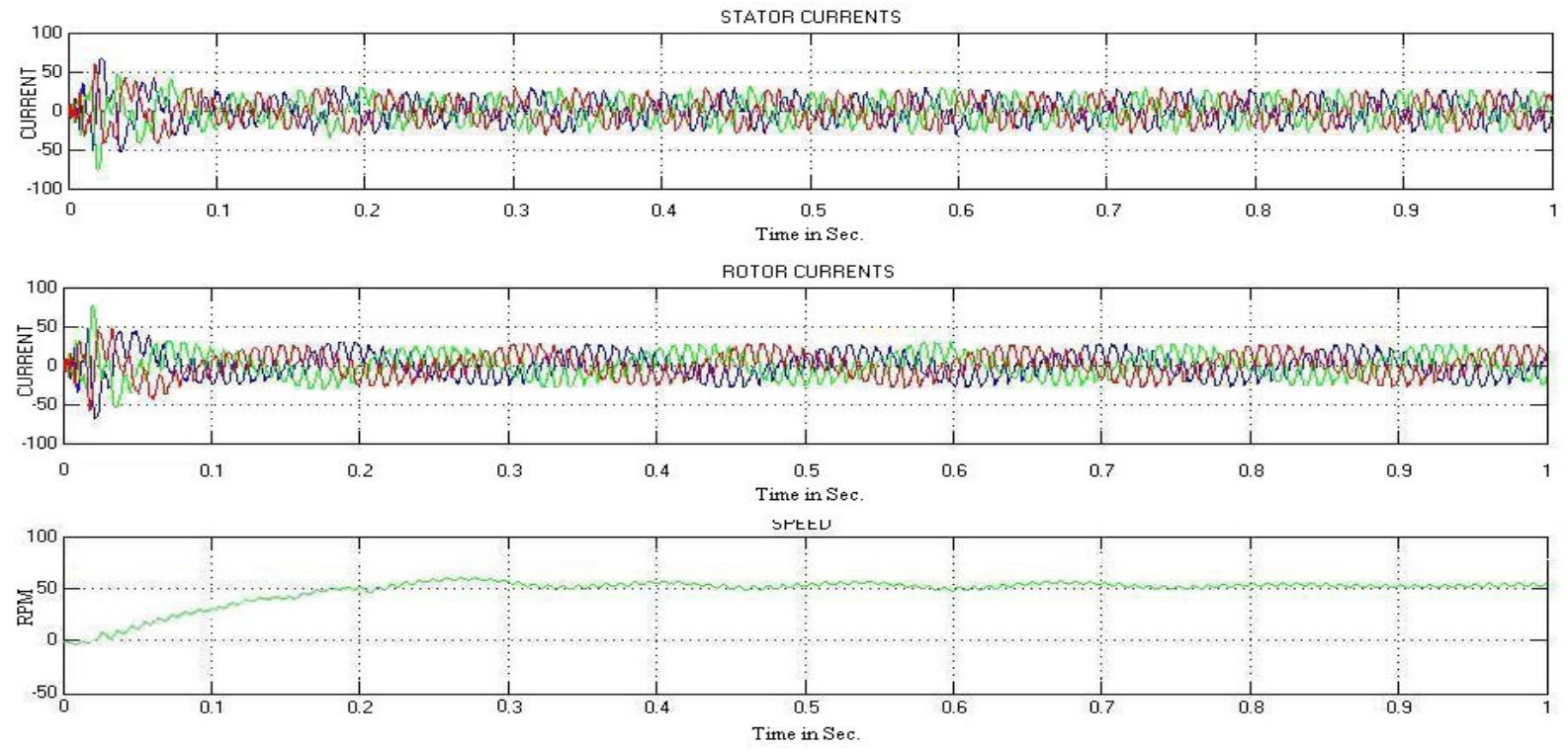

Fig. 10 Stator voltages and currents, Rotor currents and Speed Variation with respect to Time Response for stator side control alone for $\omega_{\mathrm{r}}=\mathbf{5 0} \mathrm{rad} / \mathrm{sec}$
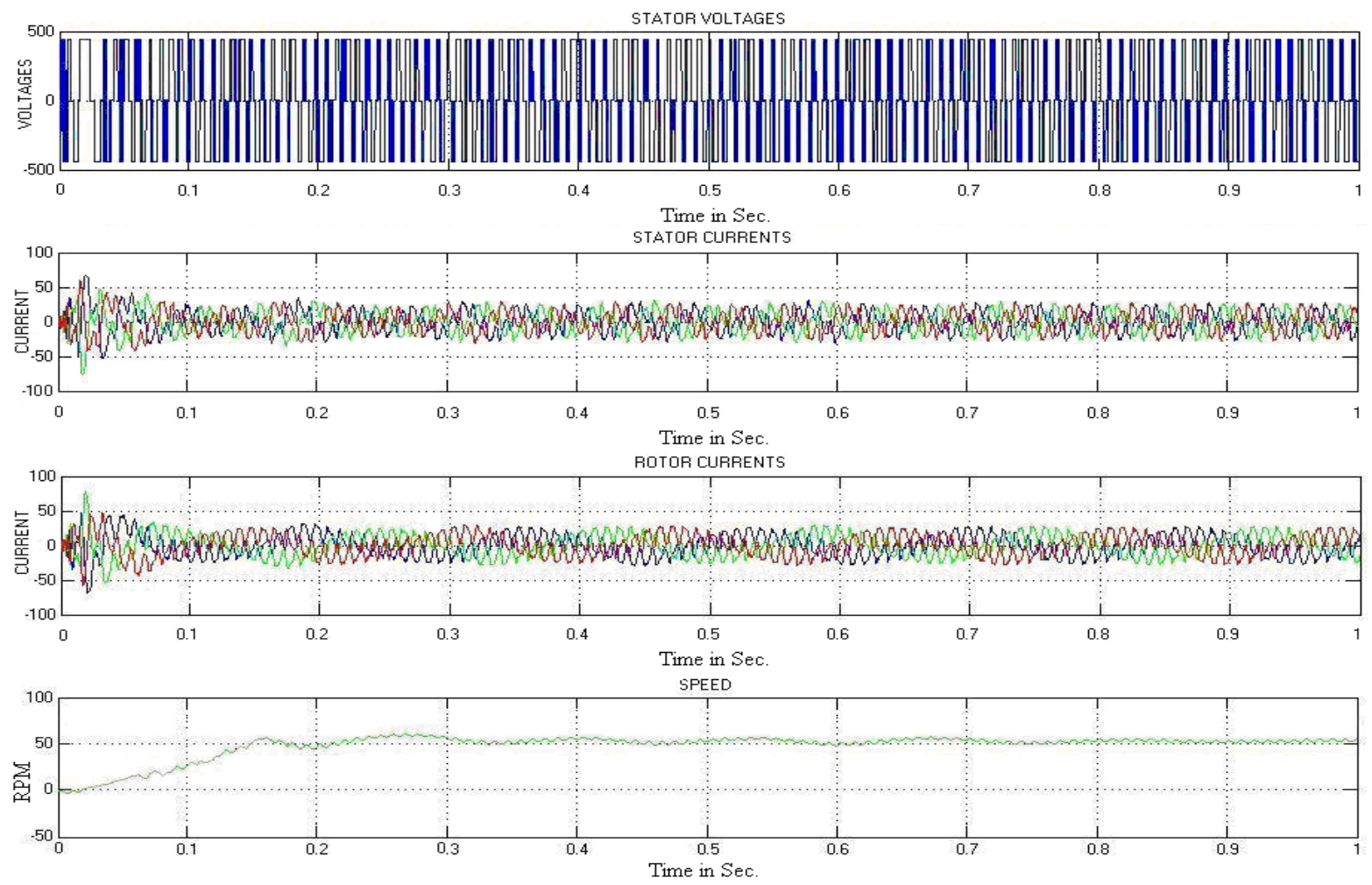

Fig. 11 Stator voltages and currents, Rotor currents and Speed Variation with respect to Time Response for Rotor side control alone for $\omega_{\mathrm{r}}=\mathbf{5 0} \mathrm{rad} / \mathrm{sec}$ 


\begin{tabular}{|c|c|c|c|c|c|c|c|}
\hline \multicolumn{8}{|c|}{$\mathbf{i}_{\mathbf{q s}}$} \\
\hline & NB & NM & NS & $\mathbf{Z}$ & PS & PM & PB \\
\hline NB & NVB & NVB & NVB & $\mathrm{NB}$ & $\mathrm{NM}$ & NS & $\mathrm{ZE}$ \\
\hline $\begin{array}{l}\mathbf{N} \\
\mathbf{M}\end{array}$ & NVB & NVB & NB & NM & NS & $\mathrm{ZE}$ & PS \\
\hline NS & NVB & NB & $\mathrm{NM}$ & NS & $\mathrm{ZE}$ & PS & PM \\
\hline $\mathbf{Z}$ & NB & NM & NS & ZE & PS & PM & $\mathrm{PB}$ \\
\hline PS & NM & NS & ZE & PS & PM & PB & PVB \\
\hline $\begin{array}{c}\mathbf{P} \\
\mathbf{M}\end{array}$ & NS & ZE & PS & $\mathrm{PM}$ & PB & PVB & PVB \\
\hline PB & $\mathrm{ZE}$ & PS & PM & $\mathrm{PB}$ & PVB & PVB & PVB \\
\hline
\end{tabular}

\section{RESULTS AND DISCUSSION}

The proposed model has been simulated using Matlab/simulink toolbox. The fuzzy and PID controllers have been designed for stator and rotor side inverters and the proposed system was tested. Stator voltages and currents, Rotor currents and Speed Variations considering stator and rotor control acting separately are shown in figure 10,11and 12 respectively. The expanded view is shown in Figure 13.

The proposed model including fuzzy controller, PID controller and inverters has been simulated using MATLAB simulation. The specification of WRIM motor used for simulation is given in Table 2.

Table 2. WRIM Specifications

\begin{tabular}{|c|c|}
\hline WRPM Parameters & Value \\
\hline Nominal power(Pn) & $3 \mathrm{HP}$ \\
Stator resistance (Rs) & $0.435 \Omega$ \\
Rotor resistance( Rr) & $0.816 \Omega$ \\
Stator inductance( Ls) & $0.002 \mathrm{H}$ \\
Rotor inductance( Lr) & $0.002 \mathrm{H}$ \\
Mutual inductance( Lm) & $69.31 \mathrm{mH}$ \\
Rotor inertia(J) & $0.00819 \mathrm{~kg} \cdot \mathrm{m}^{2}$ \\
Number of pole pairs(2p) & 2 \\
\hline
\end{tabular}

From the response shown in figure 9 when the stator Fuzzy controller is acting alone, the rise time is $0.2 \mathrm{sec}$ and the maximum peak overshoot is $2.5 \%$

When the Rotor PID controller alone is acting the rise time is $0.18 \mathrm{sec}$ and the maximum peak overshoot is $3.35 \%$ which is clearly seen from the simulated output. Figure 11 shows the wave forms of Stator voltages and currents, Rotor currents and Speed Variation with respect to time for Rotor PID control for $\omega_{\mathrm{r}}=50 \mathrm{rad} / \mathrm{sec}$.

The magnified views at two different time interval are shown in figure 13 and 14.

From the Comparison the proposed controllers when acting together the rise time is less $(0.10 \mathrm{sec})$ than the controllers acting independently $(0.20 \mathrm{sec}$ and $0.18 \mathrm{sec})$. Similarly the peak overshoot is also less when the controllers acting together. Moreover the proposed system is simulated for higher power rating machine and the motor parameters are shown in the Table 3.

Table-3. Performance Comparison of proposed system with the action of controllers for the speed $\omega_{\mathrm{r}}=50 \mathrm{rad} / \mathrm{sec}$.

\begin{tabular}{|c|c|c|c|}
\hline \multirow{2}{*}{ Parameters } & \multicolumn{3}{|c|}{ Controllers } \\
\cline { 2 - 4 } & $\begin{array}{c}\text { Stator } \\
\text { Fuzzy }\end{array}$ & $\begin{array}{c}\text { Rotor } \\
\text { PID }\end{array}$ & $\begin{array}{c}\text { Both } \\
\text { Fuzzy-PID }\end{array}$ \\
\hline $\begin{array}{c}\text { Rise time in } \\
\text { Sec }\end{array}$ & 0.2 & 0.18 & 0.10 \\
\hline $\begin{array}{c}\text { Max. Over } \\
\text { Shoot in \% }\end{array}$ & 2.5 & 3.35 & 1.85 \\
\hline
\end{tabular}



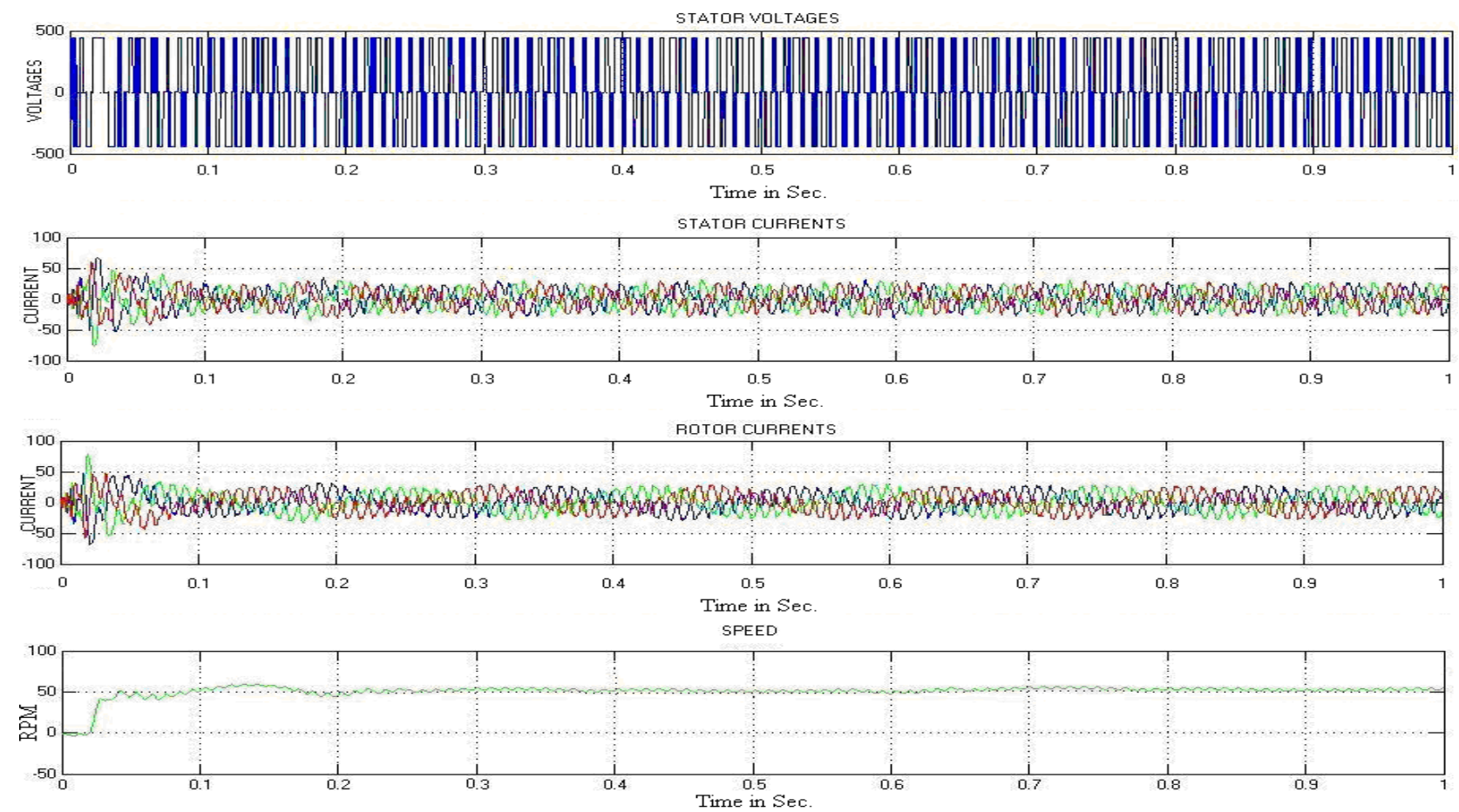

Fig. 12 Stator voltages and currents, Rotor currents and Speed Variation with respect to Time Response for both side control for $\omega_{\mathrm{r}}=50 \mathrm{r} / \mathrm{sec}$
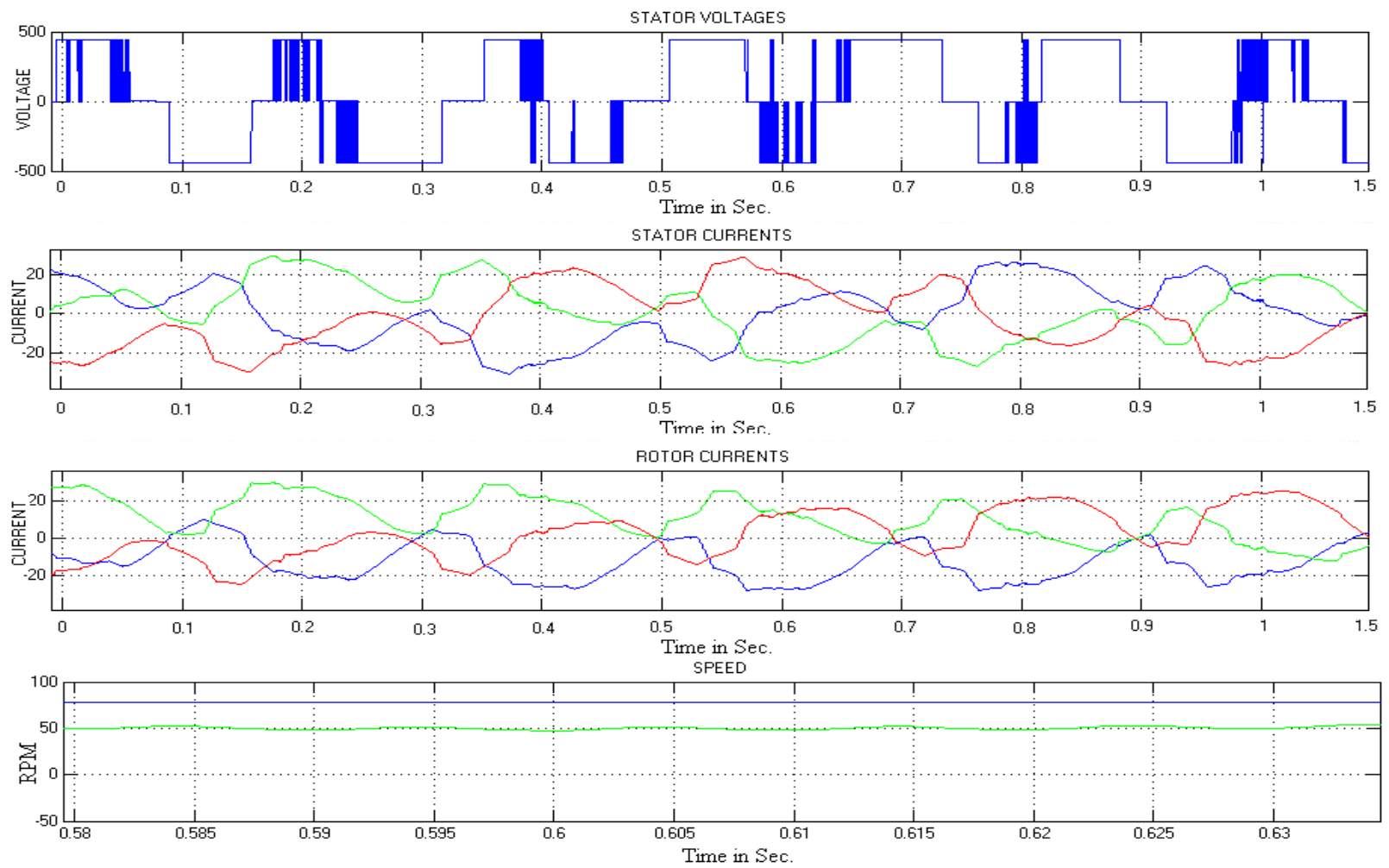

Fig.13 Expanded view 1 of Stator voltages and currents, Rotor currents and Speed Variation with respect to Time Response for both side control for $\omega_{\mathrm{r}}=50 \mathrm{r} / \mathrm{sec}$ 

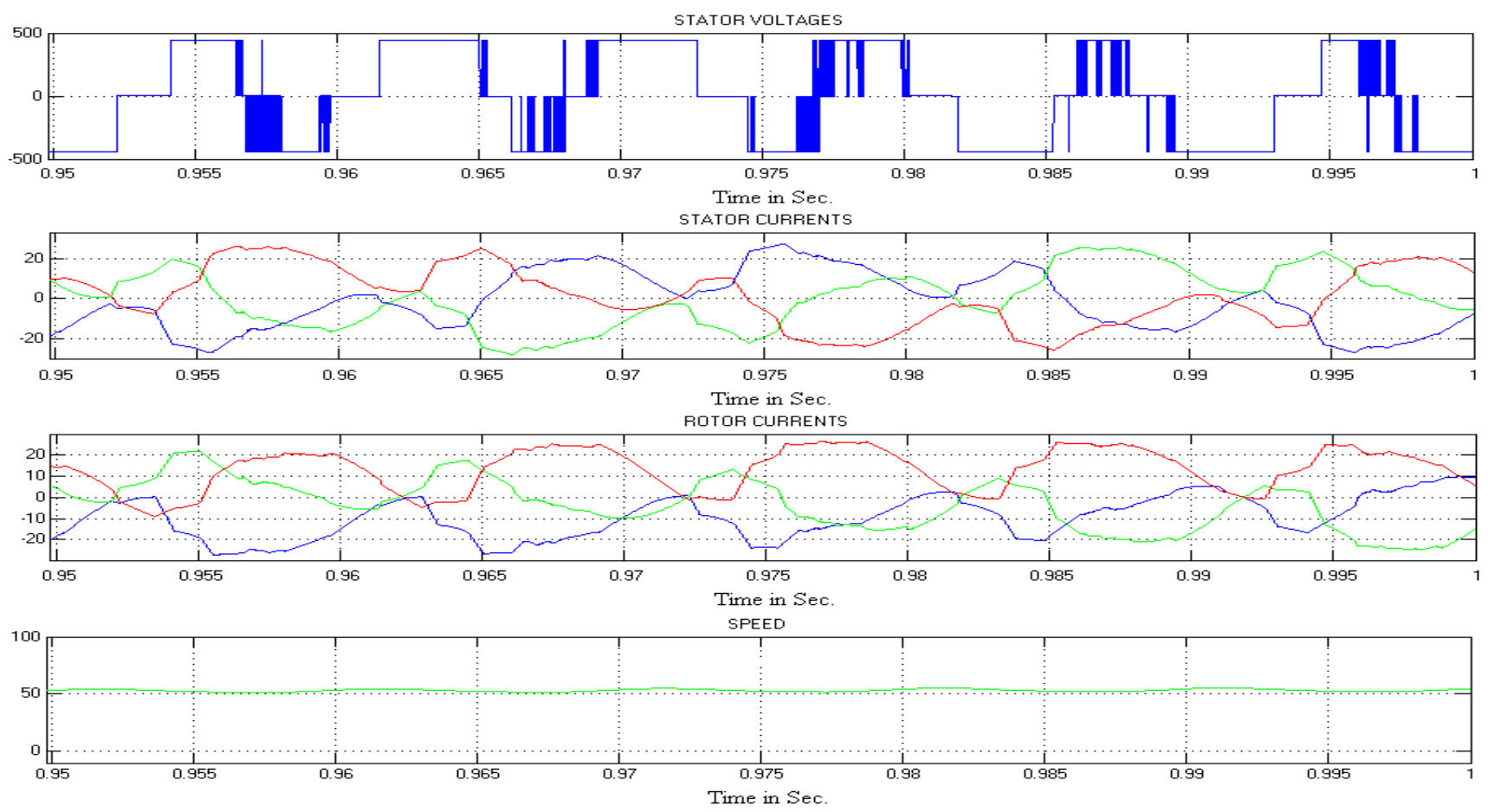

Fig. 14 Expanded view 2 of Stator voltages, Stator currents, Rotor currents and Speed Variation with respect to Time Response for both side control for $\omega_{\mathrm{r}}=50 \mathrm{r} / \mathrm{sec}$

\section{CONCLUSION}

The performance of the two input fuzzy logic based FOC for stator side inverter and PID based FOC for rotor side inverter of Double Inverter Fed WRIM is presented in this paper. The dynamic speed response of WRIM with fuzzy and PID controller was estimated and found that the speed can be controlled effectively with the improved performance. The analysis provides the various useful parameters and the information for effective use of proposed system.

\section{REFERENCES}

[1] T.Wildi, Electrical Machines, Drives and Power Systems $5^{\text {th }}$ ed., Prentice Hall, New Jersey 2002.

[2] Bimal K. Bose,Modern Power Electronics and AC Drives, Pearson Education Asia, 2002.

[3] Muhammad H.Rashid, Power electronics circuits, devices and applications, 2d edition, Prentice-Hall, 1993.

[4] R. Krishnan, Electric Motor Drives Modeling Analysis and Control, Prentice-Hall, Inc., 2001.

[5] G D Marques and P Verdelho, “A Simple Slip-power Recovery System with a dc Voltage Intermediate Circuit and Reduced Harmonics on the Mains" IEEE Transaction on Industrial Electronics, vol 47, no 1, February 2000, pp 123-132.

[6] Y Kawabata, E Ejiogu and T Kawabata. "Vector Controlled Double-Inverter Fed Wound Rotor Induction
Motor Suitable for High Power Drive" IEEE Transaction on Industry Applications, vol 35, no 5, September/October1999, pp 1058-1066.

[7] Gautam Poddar and V. T. Ranganathan "Sensorless FieldOriented Control for Double-Inverter-Fed Wound-Rotor Induction Motor Drive" IEEE Transactions On Industrial Electronics, Vol. 51, No. 5, October 2004.

[8] Gautam Poddar and V. T. Ranganathan, "Sensorless Double-Inverter-Fed Wound-Rotor Induction-Machine Drive" IEEE Transactions On Industrial Electronics, Vol. 53, No. 1, February 2006.

[9] Rajib Datta and V. T. Ranganathan, "A Simple PositionSensorless Algorithm for Rotor-Side Field-Oriented Control of Wound-Rotor Induction Machine" IEEE Transactions On Industrial Electronics, Vol. 48, No. 4, August 2001

[10] Rajani K. Mudi and Nikhil R. Pal, Member, "A Robust Self-Tuning Scheme for PI- and PD-Type Fuzzy Controllers" IEEE Transactions On Fuzzy Systems, VOL. 7, NO. 1, FEBRUARY 1999. Pages 2-16.

[11] Jabri, Majed; Chouiref, Houda; Jerbi, Houssem; Benhadj Braiek, Naceur; "Fuzzy logic parameter estimation of an electrical system" Systems, Signals and Devices, 2008. IEEE SSD 2008. 5th International Multi-Conference on 20-22 July 2008 Page(s):1 - 6 Digital Object Identifier 10.1109/SSD.2008.4632881. 
[12] Dimiter Drainkov, Hans Hellendoorn and Michael Reinfrank, An Introduction to Fuzzy Control, Narosa Publishing House, 1996.

[13] Denai and Attia, (2002) "Fuzzy and Neural Control of an Induction Motor", Int. Journal on Appl. Math. Comput. Sci., Vol. 12, No.2, 221-233.

[14] Marcelo Godoy Simoes, (1997)) "Fuzzy Logic Based Intelligent Control of a Variable Speed Cage Machine
Wind Generation System" IEEE Transactions On Power Electronics, Vol. 12.

[15] Philip.T.Krein, Elements of power Electronics, Oxford University Press, 1998.

[16] I.Boldea and S.A.Nasar, Vector control of AC Drives, CRC Press,NY,1992. 